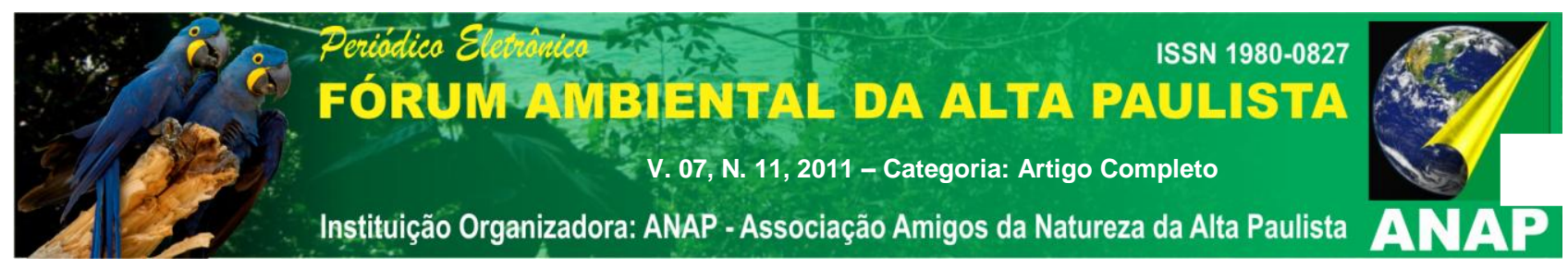

\title{
MEIO AMBIENTE E COMPETITIVIDADE NAS INDÚSTRIAS: INOVAÇÃO E VANTAGENS ${ }^{1}$
}

\author{
Marcileia Aparecida Antunes ${ }^{2}$
}

\begin{abstract}
RESUMO: Este artigo tem como objetivo ressaltar para a indústria a importância da padronização de produtos e serviços ecologicamente corretos e de menor impacto ao meio ambiente. Os conceitos de produtos e serviços que tenham como preocupação as relações de meio ambiente e uso racional de recursos são cada vez mais exigidos por um mercado consumidor consciente e pró ativo. Nesse contexto de aprimorar bens e serviços que atendam a exigência desse novo modelo de mercado consumidor, a estratégia de adoção de uma Produção mais Limpa ( $\mathrm{PML}$ ou $\mathrm{P}+\mathrm{L}$ ) culmina com a geração de inovações e competitividade para as empresas, que a partir do momento que começam a se preocupar com as questões ambientais e tomam como ponto de partida que os princípios da PML usufruem de um processo de melhoria contínua, o que propicia o surgimento de inovações em todos os setores tais como: processo, produção, administração, logística e etc. A PML estimula o surgimento de inovações e estas facilitam o alcance da competitividade.
\end{abstract}

Palavras chave: Produção mais limpa; Competitividade; Questões ambientais; Industrialização; Expansão mercadológica.

\section{INTRODUÇÃO}

A revolução industrial, iniciada no final do século XVIII na Inglaterra, foi o marco do conceito de produção em massa onde as ferramentas de trabalho foram substituídas pelas máquinas e o sistema fabril substituiu a fabricação doméstica. Atrelada às pesquisas científicas, as fábricas passaram a dispor para as pessoas uma infinidade de materiais que tinham como foco atender a demanda de um

\footnotetext{
${ }^{1}$ Artigo apresentado à disciplina Metodologia de Pesquisa Científica e Elaboração de TCC, ministrada pela professora Dra. Juliana Alves Magaldi como requisito parcial para obtenção do título de Especialista em Gestão Ambiental em Problemas Urbanos.

${ }^{2}$ Tecnóloga em Meio Ambiente pela Universidade Presidente Antônio Carlos de Juiz de Fora/MG e Pós-Graduanda em Gestão Ambiental em Problemas Urbanos pela Faculdade Estácio de Sá de Juiz de Fora/MG.
} 
mercado consumidor em expansão que culminava com a explosão demográfica, a transição entre o feudalismo e o capitalismo, a especialização da produção e o avanço tecnológico (MANTOUX, s/d).

Assim, foi dada a largada para o uso de matéria prima extraída de fontes naturais em grande escala e com o agravante desses recursos serem utilizados com técnicas pouco sustentáveis. Durante décadas a visão era a de que a ascensão econômica proporcionaria melhor qualidade de vida para a sociedade. Porém, essa mesma sociedade percebeu que o crescimento econômico desenfreado estava causando danos irreversíveis aos ecossistemas. Esse novo paradigma deve-se à "reviravolta nos modos de pensar e agir, proporcionado pelo crescimento da consciência ecológica, na sociedade, no governo e nas próprias empresas que passaram a incorporar essa orientação em suas estratégias" (DONAIRE, 1995, p.11).

Porém, uma nova perspectiva tomou características reais nos anos 90 e se associou a melhoria ambiental a ganhos de competitividade. A sociedade em geral e as entidades governamentais passaram a exigir das empresas medidas mais atuantes no controle dos impactos ambientais gerados em sua produção o que fez com que estas implantassem sistemas de gestão ambiental em suas unidades ou se adequassem às novas normas e legislações.

Um novo paradigma começou a ser definido por empresas modelos que apresentaram uma preocupação satisfatória com o meio ambiente, com a saúde e a segurança de seus colaboradores e despertaram para a necessidade de iniciativas que determinam inovação e vantagens através da adoção de uma PML cujo princípio é o de inovar, reduzir custos e tornar o empreendimento mais enxuto e competitivo.

Baseado no modelo do Sistema de Gestão Integrada (SGI), a PML determina que um sistema de gestão bem elaborado e adotado em um primeiro momento pelo setor de direção da empresa e no segundo momento expandido para os demais setores, é potencialmente capaz de produzir resultados além dos objetivos pretendidos e com grandes chances de ser uma constante no dia a dia de todos os colaboradores que compõem a estrutura organizacional de uma empresa. 
A abordagem exposta visa conceituar a proposta de uma PML, assim como apontar os benefícios e desafios da inovação e da competitividade inerentes a tais mudanças de visão e claro, as vantagens dessa tomada de decisão.

\section{CONCEITO E EXTENSÕES DE PML}

A iniciativa tomada pelas empresas que entendem que a ascensão econômica e o alcance dos objetivos pretendidos estão intrinsecamente ligados ao uso racional de matéria e energia tem como base os princípios do processo de PML que, em síntese, expressa o seguinte propósito: aplicação continuada de uma estratégia preventiva e integrada aos processos, produtos a serviços, com o objetivo de aumentar a ecoeficiência e reduzir os riscos para o homem e para o meio ambiente.

Organizações nacionais e internacionais como a Unidos Agência de Proteção Ambiental/Programa das Nações Unidas para o Ambiente ${ }^{3}$ (UNIDO/UNEP, 1995), o Greenpeace, a Companhia de Tecnologia de Saneamento Ambiental (CETESB, 2010), o Centro Nacional de Tecnologias Limpas/Serviço Nacional de Aprendizagem Industrial (CNTL/SENAI, 2010) definem alguns conceitos para uma melhor orientação e atendimento dos conceitos aplicados aos propósitos pretendidos por uma empresa que adota as técnicas de PML:

Produção Mais Limpa $(\mathrm{PML})$ = Prevenção à Poluição $(\mathrm{PP})$ : técnicas aplicadas para prevenir a geração de resíduos, efluentes e emissões. É interessante que seja aplicada em duas ou mais formas de produção. A implantação das técnicas de PML deve abranger toda a empresa, e não apenas o setor de produção.

Produção Limpa (PL): sistema de produção que não gera impacto ao meio ambiente. Trata-se de uma meta a ser perseguida, mas que não atinge sua plenitude, pois sempre haverá algum impacto.

Tecnologia Mais Limpa (TML): técnicas que provocam um menor impacto ambiental, quando comparado a outras tecnologias.

Tecnologia Limpa (TL): é a meta a ser perseguida por uma tecnologia que não causa impacto ambiental e segue a teoria da PML.

\footnotetext{
${ }^{3}$ United Nations Industrial Development/United Environmental Protection Agency.
} 


\section{Periódica \\ FÓRUN MU:J ENAL DA ALTA PAULISTA \\ V. 07, N.11, 2011 -Categoria: Artigo Completo \\ Instituiç̧ão Organizadora: ANAP - Associação Amigos da Natureza da Alta Paulista}

Tecnologia de Fim de Tubo (TFT): trata-se do uso de tecnologias para remediar os impactos ambientais decorrentes dos processos produtivos cujo objetivo é evitar que a poluição gerada dilua no meio ambiente.

De uma maneira dinâmica, a PML é a aplicação contínua de uma estratégia econômica ambiental e tecnológica integrada aos processos e produtos, com o objetivo de aumentar a eficiência no uso de matérias-primas, recursos ambientais e energia, através da não-geração, minimização ou reciclagem de resíduos gerados em um processo produtivo. Esta iniciativa induz inovação e representa um passo em direção ao desenvolvimento econômico sustentado e competitivo para as empresas assim como para toda a região que elas abrangem. A PML integra objetivos ambientais aos processos de produção e tem como resultado a redução de resíduos e as emissões em termos de quantidade e periculosidade como sugere o diagrama abaixo (figura 1, na página seguinte):

\section{Figura 1 - Fluxograma básico das fases do processo de implantação de Produção mais Limpa}

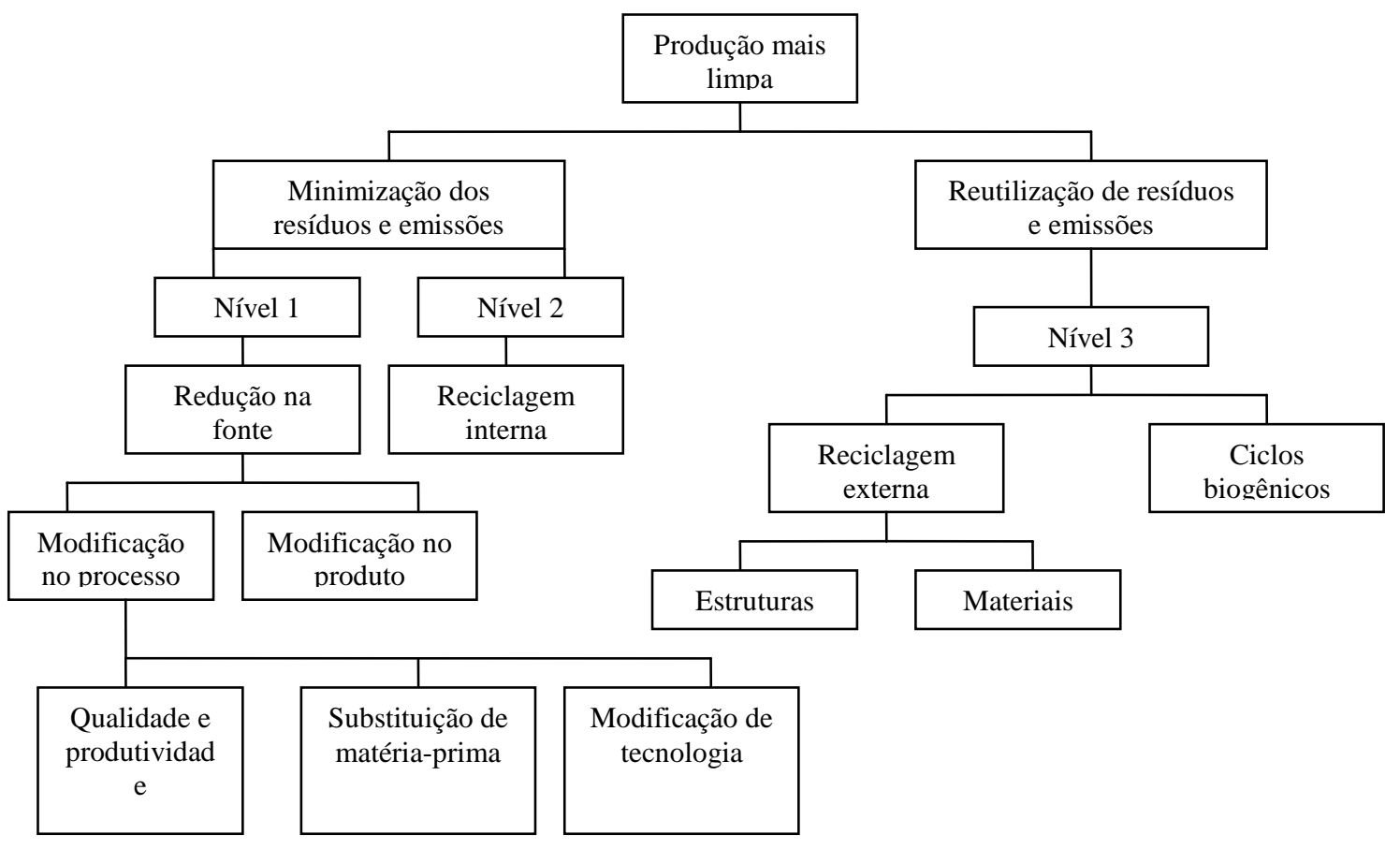

Fonte: Centro Nacional de Tecnologias Limpas (2000). 


\section{GESTÃO AMBIENTAL X TECNOLOGIAS LIMPAS $X$ PROCEDIMENTOS OPERACIONAIS}

O que caracteriza as metodologias das normas é a exigência de padronização dos procedimentos. A estratégia adotada para a padronização de procedimentos operacionais é adotar a forma como as atividades já são executadas e introduzir a elas melhoramentos ao longo do tempo, ou seja, melhoria contínua. Esse método tem que ser criteriosamente avaliado, pois a indução ao risco de padronizar técnicas consagradas ao longo do tempo pode ser elevada a "forma correta" de executar atividades e, com isso, privilegiar processos e controles associados aos enfoques de fim de tubo e o atendimento da legislação (FURTADO, 2000a).

Avaliar os procedimentos operacionais sob o ponto de vista ambiental é um grande apontador na retratação do estágio evolutivo de uma organização com relação a esta questão, uma vez que o esforço no sentido de minimizar a geração de resíduos está intimamente ligado as condicionantes da tecnologia do processo e a maneira como as operações são executadas. Tecnologias e procedimentos devem evoluir para composição de cenários progressivos e é o espaço ideal para minimização de resíduos através da otimização dos procedimentos operacionais (tecnologias limpas).

A evolução das tecnologias e procedimentos reflete as mudanças de estratégias adotadas pelas organizações na medida em que se desenvolve processo de internalização da dimensão ambiental. Este processo evolutivo começa com a estratégia reativa, passa por um estágio intermediário que é a estratégia ofensiva e termina com a estratégia inovativa (ANDRADE, 1997).

O comportamento das empresas diante das estratégias avaliadas por Andrade (1997) se estabelece da seguinte forma:

Estratégia reativa: limita a um atendimento mínimo e relutante à legislação ambiental. Sua preocupação está voltada para incorporação de equipamentos de controle da poluição na fase final da produção. A questão ambiental é tida como um custo adicional e ameaça gravemente a competitividade empresarial. 
Estratégia ofensiva: o principal foco é a prevenção da poluição, a redução do consumo de recursos e o cumprimento das exigências legislativas. Para isso são implantadas mudanças nos processos, produtos ou serviços visando uma boa imagem diante do mercado consumidor conectado às questões ambientais e, nesse mesmo contexto, deparam com a oportunidade de redução de custos da produção.

Estratégia inovativa: sua integração é ilimitada entre as questões ambientais e de negócios. A dimensão ambiental é uma função de toda a administração e é encarada como uma oportunidade de desenvolvimento, produção e comercialização de produtos com mudanças substanciais de desempenho ambiental e gerenciamento dos ciclos de vida útil dos mesmos.

A evolução na aplicação das etapas das estratégias citadas acima deve ter caráter bem definido e ser traduzidas em procedimentos padronizados compatíveis com os princípios e realidade de cada empresa, pois, do contrário, incorrerá no risco da obsolescência uma vez que a realidade é sempre mutável, o que não ocorre com o padrão. O norteador de uma PML está em prevenir a geração de resíduos e todos os desdobramentos quanto ao processo, produto, manejo do resíduo industrial, relacionamento com os clientes e fornecedores e a política ambiental da empresa (FURTADO, 2010b).

\section{VANTAGENS COMPETITIVAS E A INOVAÇÃO}

A chave mestre de qualquer decisão que uma empresa pretende tomar está na expectativa de que estas novas atitudes irão conduzi-la ao mercado de negócios. Assim, tem-se que o mercado é movido por expectativas que nada mais é que uma "miríade de reações baseada na informação objetiva e em interpretações subjetivas" (PAULI, 1996, p.48).

O ponto de equilíbrio entre a angústia e a incerteza que envolve todo e qualquer processo de tomada de decisão está nas informações e interpretações que tem como produto final a capacidade de inovar. As empresas que assumem esta posição sofrem a ação de seu meio ambiente, mas também podem influenciar este mesmo meio ambiente a seu favor e um caminho bastante promissor são as 


\section{Periódica \\ FÓRUMUAMIJNA LA ALTA PAULISTA \\ ISSN 1980-0827 \\ V. 07, N. 11, 2011 - Categoria: Artigo Completo \\ Instituição Organizadora: ANAP - Associação Amigos da Natureza da Alta Paulista}

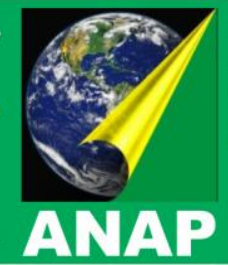

alternativas de uma PML que apontam dois aspectos importantes para a vantagem competitiva: a empresa ter baixos custos e um alto volume de vendas. Essas combinações de resultados definem o tempo de entrada no mercado e o nível de comprometimento, gerando novos padrões de produtos ou obtendo preferências em relação das matérias primas, capacidade de produção e consumidores. Esses fatores podem habilitar uma empresa a focar-se e dominar um nicho particular no mercado, com baixos custos ou produtos diferenciados, ou ambos (PORTER apud HART, 1996, apud MELLO e NASCIMENTO, 2010).

A competição para o futuro sugerida por Hamel e Prahalad (1995) é de que a empresa precisa se preocupar não somente com lucratividade no presente e o crescimento em médio prazo, mas também com a sua posição no futuro e a vantagem competitiva. Essa visão aponta para estratégias explícitas sobre como a empresa irá proceder quando a estratégia atual se tornar obsoleta exigindo um processo de inovação constante.

Justificando essa teoria, os fatores crescimento populacional e aumento nas atividades de produção das empresas pressionam o uso dos recursos naturais gerando a degradação do meio ambiente. Essa combinação de resultados promove um desafio instigante para as próximas décadas: a mudança na natureza das atividades econômicas ou o perigo de alterações irreversíveis ao sistema ecológico do planeta. A grande investida das empresas está em criar novos conceitos de estratégia de produção e a base para obtenção da vantagem competitiva está intimamente ligada às capacidades emergentes como: redução de resíduos, design de produtos e cooperação tecnológica.

Para obter a relevância da teoria dos recursos internos, a empresa deve internalizar os desafios criados pelo ambiente natural, adotando a ideia da racionalidade ambiental através da orientação dos recursos e das capacidades como fontes sustentáveis de vantagem competitiva.

\section{BENEFÍCIOS E BARREIRAS DE INVESTIMENTOS EM PML}

A característica básica de todo investimento reside na relação custo $x$ benefício. $\mathrm{E}$ a decisão de investir em PML segue fielmente este princípio. $\mathrm{A}$ 
implantação da estrutura para obtenção de PML gera um ônus inicial significativo, mas os benefícios colhidos a partir do aumento da eficiência nos processos, no consumo de matérias primas e energia, na redução de resíduos e emissões de contaminantes traduzem em potencial ganhos diretos no processo de produção e ganho indireto pela eliminação de custos adicionais atrelados ao tratamento e disposição final de resíduos com prazos curtos de amortização dos investimentos.

A relutância para se praticar a PML pode ser orientada pelos seguintes obstáculos: resistência à mudança; falta de informação sobre o programa e os processos; o desleixo das políticas nacionais que dêem suporte as atividades de PML; visão caótica de custos ambientais $x$ investimentos; resistência em investimentos de novas tecnologias.

Para a UNIDO/UNEP (1995), as empresas possuem uma visão consumista e relacionam a implantação de produção mais limpa a esse apego, quando na realidade, melhorias em práticas de operação e mudanças simples em processos resultariam em $50 \%$ a mais em eficiências e custo de produtividade.

\section{CONCLUSÃO}

A PML é uma técnica de aplicação contínua e exige a mobilização de toda a organização uma vez que requer mudanças na cultura onde está sendo implantada. E isto afeta diretamente desde a menor hierarquia até o principal executivo da empresa exigindo uma mudança na concepção de produção e de ambiente natural.

A prática de PML, geralmente, oferece redução nos custos e melhora a eficiência das operações, levando às organizações a alcançar suas metas econômicas, gerando inovações e vantagens competitivas. Esse desfecho pode ser explicado por situações que permeiam pelos seguintes ideais: com o planejamento de uso racional dos recursos, até mesmo os resíduos podem ser reaproveitados, utilizando-os para a co-geração de energia, extraindo substâncias reutilizáveis e reciclando materiais.

Um ajuste no ciclo de vida dos produtos pode ser um fator relevante no controle de desperdício e na fidelidade dos consumidores. O excesso de embalagens e o descarte de produtos que requerem um alto custo interferem em 

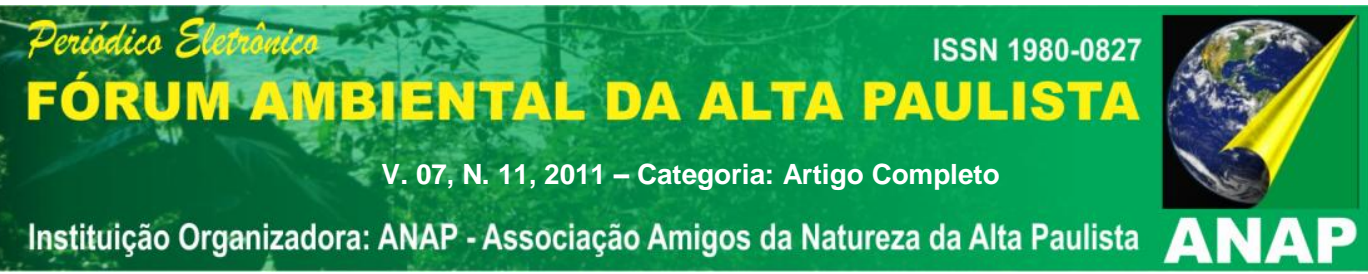

seu preço final fazendo com que os consumidores paguem pela má utilização dos recursos.

Assim, a utilização racional dos recursos ganha projeções reais através de inovações, que aumentam a produtividade e tornam a empresa mais competitiva, seja na redução de custos, ou pela melhoria de seus produtos que pelos quais os consumidores se dispõem a pagar mais.

\section{REFERÊNCIAS}

ANDRADE, J.C.S. Tipos de estratégias ambientais empresariais. In: Tecbahia (Revista Baiana de Tecnologia). v.12, no2, p.71-88. Camaçari, 1997.

. In: Revista de Gestão (1981). Disponível em: <htpp//www.funge.com.br>. Acesso em: 25 ago. 2010.

BRANCO, Samuel Murgel. Meio Ambiente uma questão de moral. São Paulo: Oak, 2002.

CETESB. Produção e consumo sustentável. Disponível em: <http://www.cetesb.sp.gov.br>. Acesso em: 16 set. 2010.

CENTRO NACIONAL DE TECNOLOGIAS LIMPAS (CNTL). Manual 5: implantação de produção mais limpa - metodologias. Rio Grande do Sul:

Unido/Unep/CNTL/SENAI-Rs, 2000.

CNTL/SENAI. Contribuição da produção enxuta para obtenção da produção mais limpa. Disponível em: <http://www.abepro.org.br>. Acesso em: 18 set. 2010.

DONAIRE, D. Gestão Ambiental na empresa. São Paulo: Atlas, 1995.

FURTADO, João S. Administração da ecoeficiência em empresas no Brasil: perspectivas e necessidades. Disponível em: <htpp//www.teclim.ufba.br/jsfurtado. Acesso em: 03 set. 2010a.

ISO 14001 e produção limpa, porém distintos de seus propósitos e métodos. Disponível em: <www.vanzolini.org.br/produçãolimpa>. Acesso em: 15 ago. 2010b.

HAMEL, G; PRAHALAD, C.K. Competindo pelo futuro: estratégia inovadora para obter e controle do seu setor e criar os mercados de amanhã. Rio de Janeiro:

Campus, 1995. 
PAULI, G. Emissão zero: a busca de novos paradigmas. O que os negócios podem oferecer a sociedade. Porto Alegre: Edipucrs, 1996.

MANTOUX, P. A revolução industrial no século XVIII. São Paulo: Hucitec, s/d.

MELLO, M. C. A. de; NASCIMENTO, L. F. Produção mais limpa: um impulso para inovação e a obtenção de vantagens competitivas. Disponível em:

<http://www.abepro.org.br/biblioteca/ENEGEP2002_TR100_0846.pdf>. Acesso em: 14 ago. 2010.

SEBRAE ET AL. Gestão ambiental: compromisso da empresa. São Paulo. 1996, no 1-8. Disponível em: <http://www.teclim.ufba.br/jsfurtado>. Acesso em: 14 ago. 2010.

UNIDO/UNEP. Manual de avaliação de P+L. Trad. CNTL/SENAI. Porto Alegre: SENAI, 1995.

VERNIER, Jacques. O meio ambiente. Trad. Marina Appenzeller. Campinas: Papirus, 1994. 